\title{
Educaçáo e Estatística: uma proposta de abordagem transdisciplinar e emancipadora
}

\author{
Uyara Soares Cavalcanti Teixeira $^{1}$ \\ https://orcid.org/0000-0002-2141-964X \\ Ivone Garcia Barbosa ${ }^{2}$ \\ https://orcid.org/0000-0001-7194-6061 \\ Ricardo Antonio Gonçalves Teixeira ${ }^{3}$ \\ https://orcid.org/0000-0002-1603-2088 \\ Patricia Brieger Rocabado ${ }^{4}$ \\ https://orcid.org/0000-0002-7326-2963
}

\section{Resumo}

O presente artigo é resultado de uma pesquisa sobre educação e estatística, realizada em parceria entre a Faculdade de Educaçáo da Universidade Federal de Goiás, via Programa de PósGraduação em Educação (PPGE/FE/UFG), e uma escola da rede pública estadual de educação localizada na capital goiana, no período de 2018 a 2019. Enquanto objetivo, propóe contribuir com o processo de formaçáo de estudantes, a partir do desenvolvimento de práticas aplicadas e inovadoras para o ensino de estatística. A experiência da vivência em pesquisa, buscou evidenciar o processo de transformaçáo dos atores-autores do processo de investigaçáo e contribuir com a formaçáo de indivíduos autônomos e críticos, a partir de problemas que é próprio e reconhecido pela comunidade que com eles vivem, entendendo que o ato de pesquisar é essencial no processo de aprendizagem. A pesquisa, de natureza qualitativa, valeu-se da Pesquisa-Açáo Integral e Sistêmica (PAIS) e contou com a participação dos professores da terceira série do Ensino Médio, a coordenadora pedagógica da escola, estudantes de mestrado e doutorado em educação da Faculdade de Educação da UFG. Enquanto resultados, para além da aprendizagem dos conteúdos de estatística, a proposta transdisciplinar, proporcionou momentos de formaçáo, a partir do engajamento e trabalho coletivo e aproximaçóes entre

\footnotetext{
${ }^{1}$ Professora da Secretaria de Estado da Educaçāo de Goiás. Membro do Núcleo de Estudos e Pesquisas da Infância e sua Educaçāo em Diferentes Contextos (NEPIEC/FE/UFG).

${ }^{2}$ Professora da Faculdade de Educaçấo e do Programa de Pós-Graduaçāo em Educação da UFG. Coordenadora do NEPIEC/FE/UFG.

${ }^{3}$ Professor da Faculdade de Educaçáo e do Programa de Pós-Graduação em Educaçáo da UFG, Goiás, Brasil.

${ }^{4}$ Diretora Adjunta de Doutorado e Pós-doutorado e a Licenciada da Universidad Mayor de San Andres, La Paz, Bolívia.
} 
professores, alunos, escola e universidade; provocou importantes construçóes e significativas mudanças nos indivíduos e no coletivo da escola.

Palavras-chave: Educação estatística, Transdisciplinaridade, Formação, Mudança.

\title{
Education and statistics: a transdisciplinary and transformative approach
}

\begin{abstract}
The article being presented is the result of a research on education and statistics, carried out in partnership between the Faculdade de Educação da Universidade Federal de Goiás, at Programa de Pós-Graduação em Educação (PPGE/FE/UFG), and a public school state school located in Goiâna, from 2018 to 2019 . The study aimed to contribute to the process of training students, from the development of applied and innovative practices for teaching statistics. The research experience sought to highlight the transformation process of the actors-authors of the research process and contribute to the formation of autonomous and critical individuals, based on problems that are proper and recognized by the community that live with them, understanding that the act research is essential in the learning process. Methodologically, the qualitative research used the Integral and Systemic Action Research and counted on the participation of teachers from the third grade of High School, the school's pedagogical coordinator, master's and doctoral students in education at the Faculty of Education at UFG. In addition to learning the contents of statistics, the transdisciplinary proposal provided moments of training, from the engagement and collective work and approximations between teachers, students, school and university; it provoked important constructions and significant changes in the individuals and the collective of the school.
\end{abstract}

Keywords: Statistical Education, Transdisciplinarity, Formation, Change.

\section{Introduçáo}

No vasto repertório de estudos sobre a educação brasileira encontra-se a assertiva de que, na contramão de uma prática conteudista, é possível pensar uma proposta de ensino transformadora e de caráter emancipatório, exigindo por parte de professores, gestores, estudantes e da comunidade escolar a assunção de uma postura mais ativa, reflexiva, crítica diante das questôes que se apresentam no processo educativo.

Na perspectiva de Paulo Freire (1979a) a mudança é compreendida como tema gerador da prática teórica e se apresenta como pauta da consciência, à medida que os diferentes sujeitos sociais se envolvem na busca coletiva por uma sociedade mais justa e igualitária. Dois aspectos são aqui pertinentes de serem salientados. O primeiro deles diz respeito ao desejo de mudança, que nada tem de natural e ato puramente espontâneo, sendo constantemente provocado pela reflexão e pelo seu suporte teórico-científico. $\mathrm{O}$ outro aspecto, dialeticamente relacionado ao já enunciado, implica no 
reconhecimento de que toda realidade é multideterminada, está em pleno movimento e sujeita à mutabilidade em suas diferentes dimensões.

Tendo por base essas premissas, reafirmando uma perspectiva emancipatória na educação básica, no presente texto apresentamos resultados e análises sobre uma pesquisa a respeito do desenvolvimento de práticas aplicadas e inovadoras para o ensino de estatística, na qual buscamos cotejar o processo de transformação com e pelos sujeitos na investigação, a partir de problemas que é próprio e reconhecido pela comunidade que com eles vivem. Trata-se de uma proposta realizada em parceria entre a Faculdade de Educação da Universidade Federal de Goiás, via Programa de Pós-Graduação em Educação (PPGE/FE/UFG), e uma escola da rede pública estadual de educação localizada na capital goiana. Faz-se importante ressaltar que o convite para o trabalho coletivo partiu da referida instituição escolar, via solicitação da professora de matemática, integrante da pesquisa em apresentação.

A pesquisa foi realizada no período de janeiro de 2018 a março de 2019. Atuaram como parceiros de pesquisa - denominados por atores-autores ${ }^{5}-$ os $^{-}$ professores da terceira série do Ensino Médio, a coordenadora pedagógica da escola, estudantes de mestrado e doutorado em educação da Faculdade de Educação da UFG, orientados por um professor do PPGE/FE-UFG e dos alunos das quatro terceiras séries do Ensino Médio do turno matutino da escola.

Para registro de relatos, informaçóes obtidas e comunicados em campo, utilizou-se de entrevistas formais e informais, em caráter individual e coletivo, e observação de campo, suportados por diários de campo, registros fotográficos, recursos informáticos, dentre outros.

Enquanto procedimento de investigaçáo, em função da complexidade da démarche em estudo, optou-se pela Pesquisa-Ação Integral e Sistêmica (PAIS), proposta por André Morin (2004). Conforme expóe o autor, trata-se de "uma metodologia de pesquisa que utiliza o pensamento sistêmico [...] para modelar um fenômeno complexo ativo em um ambiente igualmente em evolução, no intuito de permitir a um ator coletivo intervir nele para induzir uma mudança" (MORIN, 2004, p. 91). Nessa direção, parte-se do pressuposto de Michel Thiolent (2007, p. 31) de que a de pesquisa-ação

\footnotetext{
${ }^{5}$ A perspectiva de atores-autores apresenta uma conotação mais ampla do que participantes, no sentido que, na pesquisa-açáo, os sujeitos se constituem como protagonistas do processo de investigaçáo, cuja voz ecoa e sua vontade é respeitada. Em uma pesquisa-ação é salutar que as açóes, os registros e as produçóes sejam coletivos. A exemplo disso, a coautora deste estudo foi um dos atores-autores da pesquisa em apresentação.
} 
admite “processos de argumentação ou de 'diálogo' entre vários interlocutores".

Thiollent (2007) apresenta um processo de organização da pesquisaação em quatro fases, sendo elas: a exploratória; a principal; a de ação; e, a de avaliaçáo. Ressalta-se, diante da complexidade da proposta e riqueza dos dados, uma opção pela não construção textual em formato clássico que parte de uma estrutura teórico-metodológica para a etapa de resultados e discussóes. Em face a possibilidade de apresentar uma síntese da experiência da pesquisa pela sua dinâmica e pela natureza flexível da pesquisa-ação, optamos por uma exposição em movimento, essencialmente espiralado, em que os aspectos teóricos se encontram imbricados nos processos de análise, cuja exposição segue de organização das fases proposta por Thiollent (2007).

\section{Fase exploratória: articulaçáo entre os atores-autores}

Nesta etapa da pesquisa, também denominada como fase de identificação, foi feita a aproximação dos pesquisadores com os atores-autores. No âmbito da pesquisa, foram realizadas várias visitas à escola com o objetivo de conhecer a sua realidade, as estruturas disponíveis, o Projeto Político Pedagógico, bem como estabelecer uma linha de diálogo, planejamento e trabalho com professores, além de conhecer as turmas de terceira série envolvidas nas ações.

No processo de interação com a escola e seus diferentes atores, propusemos desenvolver um projeto de educação estatística na escola, uma tendência em educação matemática, mas que o desenho seria construído a várias mãos, a partir do entendimento, participação e colaboração de todos os envolvidos. A educação estatística, para Lima e Gonçalves (2017, p. 197), se apresenta como uma oportunidade de formação crítica "sobretudo, por possibilitar uma postura ativa dos alunos enquanto pesquisadores e pela adoção de uma abordagem da matemática como ferramenta para resolução de problemas do dia a dia desses estudantes”. Para os autores, a educação estatística favorece a vivência com a pesquisa e com temas que expressam o mundo real, levando os estudantes a refletirem/questionarem a sua realidade.

A pedagogia para as matemáticas está relacionada com a necessidade de ensinar aos estudantes uma forma inteligente de contribuir com o progresso da sociedade, é importante compreender que a matemática e as demais ciências não são independentes da sociedade. 
Em paralelo à atividade de inserção na escola, ocorreu, via PPGE/FE/UFG, a oferta da disciplina intitulada "Pesquisa e análise de dados em educação", com carga-horária de 128 horas-aula que, dentre outros objetivos, visou preparar os estudantes de mestrado e doutorado para a atividade empírica no contexto da investigação. A ideia foi promover articulação síncrona entre a pesquisa na escola e a disciplina ofertada no âmbito da UFG, integrando os professores da escola, os estudantes do Ensino Médio e os de pós-graduação.

Dois importantes movimentos ocorreram, assim, de modo simultâneo: enquanto a pesquisa era "amadurecida" na escola campo, com aproximação de pessoas, participação em reuniôes, organização de planejamentos, negociação de cronogramas, na disciplina ofertada no PPGE/FE/UFG, aprofundava-se os estudos e a apropriação de conceitos teóricometodológicos, ferramentas e recursos de pesquisa. No plano da disciplina foi contemplado uma incursão em campo, porém o detalhamento só seria feito após a aproximação com a escola, com contribuição de todos, a partir de uma construção coletiva.

A construção coletiva é fundante e necessária para que os estudantes compreendam a relação dos conteúdos ensinados na escola com a sua realidade, em um movimento crítico e reflexivo, como síntese da práxis educativa, principalmente no campo da matemática que, historicamente, tem se constituído como área dominante com fim em si mesma. Faz-se necessário refletir sobre o cuidado da sobreposição do caráter técnico dos conteúdos trabalhados em relação ao fator humano e social presentes em todo o processo de formação.

Fase principal: construçáo da proposta de Educação Estatística na perspectiva transdisciplinar

Após compreender a demanda da escola para uma pesquisa de natureza interventiva, o passo seguinte foi dialogar com a professora de matemática sobre os conteúdos constantes em seu planejamento para as terceiras séries do Ensino Médio. Verificou-se que a estatística estava contemplada no terceiro dos quatro bimestres previstos no ano escolar.

Partindo da informação quanto à realização de projetos no ensino de estatística em anos anteriores, buscamos discutir com a professora sobre a viabilidade de ampliação da proposta que, até então, era exclusiva da área de matemática. Para o envolvimento de outros integrantes no projeto, seria 
necessário pensar a estatística não como mais um conteúdo de matemática a ser ensinado na escola, mas como uma proposta educacional, uma "ferramenta meio" que possibilitasse não só a sua integração com outras áreas - em uma ótica da interdisciplinaridade - mas, acima de tudo, a interação com situações práticas do mundo real, dentro de um contexto sócio-histórico-cultural, para além dos muros da escola - ao que se reconhece como transdisciplinaridade.

A transdisciplinaridade no contexto escolar, conforme indicou D’Ambrósio (2011), se apresenta como um movimento de aproximação das fragmentadas disciplinas com a realidade que abarca também o que extrapola os muros da escola, o que não raramente é desconsiderado no currículo escolar, nos tópicos abordados nos livros didáticos ou nos exames estandardizados. É preciso destituir essa dicotomia que impóe o muro como limite tácito e que se traduz na falsa ideia de que o conhecimento escolar, pretensamente acabado e "teórico" se afirma na oposição àquele não-escolar, como se este último se resumisse ao processo de transmissão autômato de um "saber prático" e desprovido de qualquer significação. Porém, na perspectiva firmada como referência na pesquisa, o conhecimento partilhado no meio escolar, assim como outros partilhados em outros meios sociais mais ou menos institucionalizados, também é marcado pela incompletude. Os conhecimentos estão ainda, em vários de seus aspectos, inacabados e, portanto, em construção, aberto às novas propostas e intervençóes coletivas.

A estatística, como área da matemática, pode ser melhor compreendida em um processo de "redescobrimento", provocado pela participação ativa e participativa dos estudantes. O vínculo estabelecido na aproximação de um saber sistematizado com problemas ou situações cotidianas que são próximas, podem lograr nos estudantes um conhecimento sistêmico e integral.

Assim, em contínuo diálogo com a professora de matemática e em parceria com o coletivo da escola, estabeleceu-se uma construção coletiva de um projeto em educação estatística, delimitando-se açôes a serem desenvolvidas ao longo do semestre letivo. Importante assinalar que nesta ótica admite-se que "há entre as estatísticas e a realidade a mesma diferença irredutível que separa todo o conhecimento do real. As estatísticas são, também elas, construçóes" (BESSA, 2014, p. 85).

Uma ideia levantada pela professora de matemática mostrou-se muito importante, indicando que as aulas de estatística pudessem oportunizar aos alunos vivenciarem as diferentes etapas de uma pesquisa, desde o levantamento das questôes de investigação, a construção do questionário, ao processo de aplicação, tabulação e análise, à produção do relatório. Para tanto, uma das estratégias essenciais para o envolvimento da comunidade escolar no 
projeto seria a integração de uma proposta pedagógica a partir de temas geradores em uma perspectiva freiriana (FREIRE,1983; 1987), ou seja, que se apresentasse como um esforço coletivo para aprofundamento de questóes significativas à realidade local. Segundo Freire (1987, p. 55), se o tema gerador proposto for realizado "por meio de uma metodologia conscientizadora, além de nos possibilitar sua apreensão, insere ou começa a inserir os homens numa forma crítica de pensarem seu mundo”.

Em reunião com a presença da coordenação pedagógica e os professores das terceiras séries do Ensino Médio, foi apresentado o projeto iniciado com abertura para adequaçóes, acréscimos ou mesmo reformulação. Um dos pontos levantados em reunião eram os temas geradores. Após debates acerca de conceitos e significados sociais, ficou definido que o levantamento inicial dos temas geradores seria feito pelos alunos da escola, sendo posteriormente selecionados, em número de seis, pelos professores e coordenaçáo.

Para o trabalho com temas geradores com envolvimento dos acadêmicos do PPGE/FE/UFG no projeto, mostrou-se necessário pensar em uma estrutura de organização que possibilitasse a realização harmônica das atividades no lócus da pesquisa. A ideia inicial era integrar os alunos da pósgraduação nos diferentes grupos formados em cada uma das salas das terceiras séries, porém tal proposição foi superada por não possibilitar a integração entre as turmas.

Para contemplar a interlocução entre as turmas, o coletivo definiu que a organização dos grupos fosse feita tendo em vista a reorganização dos alunos das terceiras séries a partir dos seis temas geradores a serem escolhidos. Como, em média, cada uma das quatro terceiras séries do turno matutino tinham quarenta alunos, formaram-se seis grupos compostos de, aproximadamente, vinte e seis alunos cada.

Os vinte e quatro alunos matriculados na disciplina do PPGE/FE/UFG também foram divididos em seis grupos, tendo quatro alunos em cada, sendo estes integrados aos grupos da escola. A função dos mestrandos e doutorandos nos grupos da escola era contribuir nas etapas a serem desenvolvidas na proposta da disciplina: aprofundamento no tema gerador; construção do questionário; aplicação do instrumento; utilização de recurso tecnológico no processamento das informaçóes; e, construção do relatório a partir da análise crítica dos dados. Ressalta-se que todos esses procedimentos de pesquisa tiveram um lugar especial na disciplina ofertada no PPGE/FE/UFG.

A metodologia a ser testada ou empregada em um estudo científico é composta de um conjunto de métodos de aprendizagem para que se possa chegar à solução dos problemas colocados pelos vários caminhos, porém cada 
método tem uma ordem lógica, que dá suporte às descobertas, relações ou bases para as análises cuja aplicação ou uso pode ter distinção entre os diferentes campos ou áreas da ciência. Os métodos didáticos, no entanto, são fruto de discussóes e avanços oriundos de diálogo e aproximaçóes do campo acadêmico com o científico, em um contexto global, mas que leva em consideração complexidades e particularidades que são locais.

Em reunião com equipe gestora e professores, sobre os temas propostos pelos alunos, realizou-se um exercício de aproximação dos mais de trinta temas que foram, por votação, reduzidos em dez. Nessa etapa não houve exclusão, mas um exercício de convergência temática. $\mathrm{Na}$ sequência, cada um dos quinze presentes na reunião votou em quatro temas e os seis mais votados foram: maioridade penal $(86,7 \%)$, inclusão escolar $(86,7 \%)$, violência na escola $(80,0 \%)$, feminicídio $(66,7 \%)$, patrimônio público $(46,7 \%)$ e saúde e meio ambiente $(33,3 \%)$.

Os professores, em comum acordo com a equipe gestora da escola, decidiram que a nova composição dos alunos em seis grupos se manteria nos dois meses de execução da etapa do projeto (outubro e novembro de 2018) inclusive para as aulas, ou seja, as quatro turmas da terceira série se transformou em seis "novas turmas". Para tanto foi necessário repensar a distribuição de professores e horário das aulas. Assim como os alunos do Ensino Médio e da pós-graduação, os professores também foram divididos por temática, sendo distribuídos de dois a três professores para cada tema.

Em dupla ou em trio - conforme composição -, os professores se propuseram dialogar com os estudantes acerca dos temas geradores. Essa atividade era essencial, pois, para a etapa de elaboração do questionário (com apoio dos mestrandos e doutorandos), deveriam aprofundar sobre o tema para elaboração das questóes. 
Figura 1. Registro de encontros para diálogo sobre os temas geradores
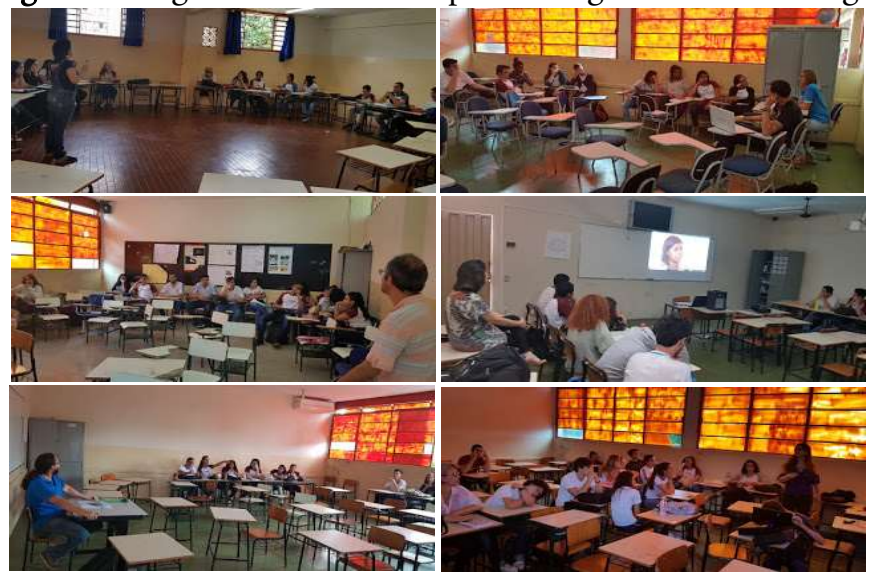

Fonte: Registro de pesquisa

No âmbito da disciplina da pós-graduação, após trabalhar as estratégias do campo de investigação, passou-se a aprofundar nas etapas da construção de um questionário com adequaçáo da linguagem e tipos de questóes a serem utilizadas no instrumento, levantamento de possibilidade de cruzamentos de dados, desenvolvimento de competência no uso de softwares de apoio ao processo de tratamento e análise dos dados.

Os acadêmicos do PPGE/FE/UFG tinham como desafio, além de dar apoio e suporte aos estudantes das terceiras séries, enquanto exercício de pesquisa, fazer a observação durante as atividades na escola e realizar entrevistas com equipe gestora, professores e alunos sobre o projeto em desenvolvimento.

Fase da açáo: aproximação dos acadêmicos de pós-graduaçáo com professores e estudantes do Ensino Médio

Antes do encontro dos estudantes da pós-graduação da UFG com professores e estudantes da escola foi necessário um processo de formaçáo e preparação previamente descrito na seção anterior. Tanto os alunos da UFG quanto da escola tinham ciência de todas as etapas do planejamento, fator que gerou, de um lado, segurança do trabalho a ser desenvolvido e, de outro, expectativas por parte de todos. Após ter-se discutido a parte operacional da elaboração e proposição de questionários, realização de entrevistas e de 
observaçóes in loco, os pós-graduandos receberam outras instruçóes sobre as atividades de suas responsabilidades, como indicamos a seguir nos diálogos estabelecidos no âmbito da disciplina de pós-graduação no PPGE/FE-UFG (22/10/2018):

A organização da visita se constitui a partir da seguinte estrutura de organização e atividades:

1) A turma do PPGE/FE/UFG foi dividida em seis grupos (G1, G2, ..., G6);

2) As turmas dos $3^{\circ}$ s anos da escola campo também foram divididas em seis grupos (G1, G2, .., G6);

3) $\mathrm{O}$ G1 dos alunos do PPGE/FE/UFG se reunirá com o G1 dos alunos da escola (com junção de todos os $3^{\circ}$ s anos); o G2 dos alunos do PPGE/FE/UFG se reunirá com o G2 dos alunos da escola e assim por diante;

4) $\mathrm{O}$ objetivo das reunióes entre os alunos da escola e do PPGE/FE/UFG é consolidar o questionário a ser aplicado no dia 09/11 (na própria escola), assim, além da visita, caberá aos alunos do PPGE/FE/UFG o acompanhamento da melhoria/adequação do questionário (como sugestão para acompanhamento fica a construçáo de um grupo no WhatsApp)

5) A fase seguinte constituirá na tabulação dos dados

6) Por fim, os dados serão analisados e transformados em relatórios a ser apresentados no dia 23/11.

Distribuição dos temas e seus respectivos grupos

Grupo 1 - Maioridade penal

Grupo 2 - Inclusão escolar

Grupo 3 - Violência na escola

Grupo 4 - Feminicídio

Grupo 5 - Patrimônio público

Grupo 6 - Saúde e meio ambiente

No dia do encontro, os professores da escola recepcionaram os alunos da pós-graduação e os conduziram para as salas de aula, em conformidade com as respectivas temáticas de trabalho. As seis novas turmas de terceira série tiveram um encontro com os alunos da pós-graduação no período das 7 h30 às $12 \mathrm{~h} 30$. Para esse momento, houve um planejamento para condução das atividades, dentre as quais destacam: apresentação pessoal, diálogo sobre o que é/como é ser estudante de graduação e pós-graduação, diálogo sobre o tema gerador trabalhado em sala e levantamento de tópicos para serem discutidos e 
analisados no sentido de composição das questôes do instrumento em elaboração.

Ressalta-se que coube a professora de matemática o trabalho prévio dos conteúdos de estatística com os alunos das terceiras séries. Os conteúdos contemplados nessa etapa abrangeram: séries estatísticas, população e amostra, organizaçáo de dados em tabelas e gráficos, medidas de tendência central, princípios de medidas de dispersão, uso de planilhas eletrônicas e elaboração de questionários via aplicativo. Em concordância com os alunos da escola, adotou-se a plataforma do Google Forms ${ }^{6}$ para a construção do instrumento e formato de aplicação - online, sendo esta viabilizada pela utilização de aparelhos móveis (smartphones ou tablets).

Embora a maioria dos alunos tivesse acesso aos aparelhos móveis (apenas cinco alunos das terceiras séries não possuíam um dos equipamentos), foi necessário agrupá-los de forma que todos pudessem participar do momento de aplicação, seja pela abordagem, exposição das questóes do instrumento, registro das respostas ou envio do pacote de dados. Como suporte, também foi necessário contemplar atividades com o uso do aplicativo Google Forms, além de viabilizar estrutura de sinal de internet para a sua operacionalização em campo de pesquisa. Concordando com a perspectiva de D’Ambrósio (2001; 2005), reafirmamos, neste caso, o papel mediador do professor, a quem coube proporcionar aos estudantes uma aproximação da matemática com a sua realidade e as experiências destes com o mundo tecnológico, compreendida como saber (ciência) e fazer (técnica), podendo proporcionar e provocar importantes mudanças no campo educacional e em suas vidas.

Embora cada grupo de alunos do PPGE/FE/UFG tenha implementado uma dinâmica própria e específica para a condução do encontro com seu grupo específico, a abertura para uma escuta sensível dos alunos das terceiras séries mostrou-se muito positiva, à medida que se apoiou na empatia que se estabeleceu a partir do diálogo, abertura à posição do "outro", aproximação, e cujo resultado constituiu-se em confiança (BARBIER, 2002). Desse modo, para além do objetivo fim da atividade proposta, os alunos da escola tiveram oportunidade de conversar sobre o percurso de uma formação em nível superior, sobre as principais barreiras, os caminhos para se chegar à pósgraduação. Essa aproximação traduz-se, como expõe Freire (1979b; 1981), no

\footnotetext{
${ }^{6}$ Trata-se de um aplicativo online disposto em uma plataforma do escritório Google Drive, de característica gratuita, que fornece estrutura de gestáo da informaçáo que viabiliza pesquisas de diferentes naturezas com uso de instrumentos como questionário, inquérito, formulário, enquete, dentre outros.
} 
diálogo e na construção, uma relação essencial no processo educativo e, por conseguinte, formativo.

Nessa etapa, observou-se que os seis grupos conseguiram avançar no aprofundamento do tema, na construção do instrumento e na organização das atividades a serem realizadas em campo. Ficou estabelecido entre os discentes da escola e da pós-graduação, por temática, um canal de comunicação, em aplicativo de grupo na rede social via celular. Por meio do canal realizaramse discussões, intervençôes e demais contribuiçôes para a construção do questionário e do estabelecimento das estratégias de abordagem.

Cabe-nos considerar no processo a preocupação de Freire (1996), para quem não se pode deixar de refletir acerca dos "riscos" que a autonomia carrega em seu âmago. Uma atividade, seja ela educacional ou de outra ordem ou meio, se for demasiada controlada pode carregar, no olhar a quem a conduz, certo ar de estabilidade, organização e ordenamento. $\mathrm{O}$ risco em questão não se caracteriza, no limite, por não dar certo ou por algum tipo de imperfeição, mas por renunciar ao caráter inovador, construtivo, problematizador e inesperado. Autonomia, nesse sentido, se caracteriza essencialmente por um ato pedagógico, capaz de proporcionar importantes e significativas aprendizagens, se apresentando, assim, como um ato de emancipação.

Em função do cronograma, os alunos tinham uma semana para construção do questionário e sua adequação no formato digital, via plataforma Google Forms, para ser encaminhado aos professores de apoio/orientadores do tema gerador para possíveis correçóes. A preocupação central na avaliação do instrumento era quanto à composição das questóes-chave ou cernes do instrumento (verificação se o conjunto de perguntas feitas contemplava a expectativa elaborada para o tema gerador proposto); adequação da linguagem (para que não fosse necessário que o inquiridor tivesse que explicar as questóes no ato da "aplicação" do instrumento); composição dos tópicos de questôes (elementos que possibilitam caracterização dos inquiridos e cruzamentos de informaçóes e dados); além do tempo gasto para sua proposição (quesito importante a ser considerado no processo de coleta de dados).

$\mathrm{O}$ registro seguinte postado no blog da turma do PPGE/FE/UFG expressa uma síntese do encontro com os alunos da escola campo. 


\section{Experiência de campo e o nosso próximo encontro}

Olá,

No dia de hoje, dia 29/10, tivemos uma ótima oportunidade de vivência de campo de pesquisa. A escola nos recebeu muito bem coordenação, professores e, principalmente, os alunos.

Foi muito gratificante vê-los engajados na ação com os adolescentes. Era explícita a troca nas relaçóes (os alunos comentaram nos corredores como foi rica essa aproximaçáo com os estudantes da UFG). Também recebi alguns feedbacks de alunos do PPGE sobre a qualidade da participação dos alunos nas discussóes.

Bom, como sabem, fiquei nos bastidores... Percebemos muitas coisas, dentre elas a curiosidade dos professores da escola em saber como eram os mestrandos e doutorandos da UFG, suas áreas de formação, linhas de pesquisa e tudo mais. No grupo de professores, havia uma doutora em sociologia e duas mestras em educaçáo, outra cursando o mestrado no CEPAE/UFG e um em pleno processo seletivo. Dois professores ficaram bastante interessados e aproveitaram o momento para saber de detalhes sobre o nosso Programa.

$\mathrm{Na}$ aula do dia 05/11 vamos dar um tempo para conversarmos sobre a experiência de campo, combinado?!

Concluída a etapa de elaboração, correção e adequação dos questionários no formato digital, o passo seguinte foi organizar a equipe para o trabalho de campo, isto é, para a proposição/ "aplicação" do instrumento. O canal de comunicação estabelecido entre os alunos da escola e os da pósgraduação foi essencial para organização dessa etapa de trabalho.

A proposição do questionário se deu no período de quatro dias no mês de novembro de 2018, nas dependências da própria escola. Ressalta-se que, naquele período, a escola encontrava-se em atividade esportiva interclasse e de realização de um projeto exposições multiculturais (artesanato, alimentação, vestimentas, dentre outros). Assim, os alunos da escola não se encontravam nas salas de aula, mas espalhados nos diferentes espaços disponíveis na escola: pátio, quadra-esportiva, laboratórios.

\section{Fase de avaliaçáo: da concepçáo aos processos e produtos}

Para desenvolver uma avaliação da pesquisa em educação, com foco em processos pedagógicos e implicação interventiva, faz-se importante considerar 
o acompanhamento permanente e integral das açóes propostas, das atitudes e empenho dos envolvidos, bem como o progresso alcançado individual e coletivamente. $\mathrm{O}$ propósito da avaliação, nesse contexto, é refletir sobre as aprendizagens, compreendida aqui não só pelo que deu certo, como também sobre o que não ocorreu conforme o planejado, fator que nos permite reavaliar e reconsiderar.

Ao avaliar o desenvolvimento do processo de desenvolvimento pesquisa podemos apresentar uma percepção da realidade vivida nos momentos de observação de campo, bem como na análise das entrevistas e relatórios produzidos.

A experiência de envolver estudantes da pós-graduação, em nível de mestrado e doutorado, com a realidade de uma escola viva, pulsante, com presença de professores interessados em provocar mudanças em sua prática educativa, trouxe importantes ganhos a todos. Os diálogos promovidos em todo processo, as trocas de experiências e de contatos estabelecidos pela/na vivência de campo, constituíram em marcos fundamentais ao contexto da pesquisa. Também se deve destacar os ganhos pedagógicos provocados pela aproximação dos estudantes do Ensino Médio com os da pós-graduação. Nesse caso, muitas foram as questóes levantadas sobre os desafios da profissão, organização para o estudo nos diferentes níveis educacionais, sobre enfrentamento dos medos e das dificuldades socioculturais e econômicas presentes na realidade dos diferentes participantes da pesquisa.

Os estudantes do Ensino Médio se organizaram em agrupamento distinto ao convencional, náo se tratava mais de $3^{\circ} \mathrm{A}, \mathrm{B}, \mathrm{C}$ ou $\mathrm{D}$, mas de grupos de investigação sobre as temáticas: maioridade penal, inclusão escolar, violência na escola, feminicídio, patrimônio público e saúde e meio ambiente. Ressalta-se que todos viviam um importante momento político que era a eleição presidencial, cujos temas eram abrangidos de calorosos debates e enfrentamentos sociais.

Da mesma forma que os estudantes, os professores da escola não mais trabalhavam individualmente seus conteúdos. Havia, então, um planejamento coletivo, com aulas divididas com outros colegas e estudantes da pósgraduação, cujo tema orientador era transdisciplinar. Como consequência desse novo modo de construir o processo de conhecimento, a escola também teve a necessidade de se reestruturar no espaço físico, em sua organização nos serviços, na distribuição dos horários das aulas, na carga-horária dos docentes. Tudo precisou ser discutido coletivamente. Nesse sentido, a participação e parceria da equipe gestora mostraram-se essencial para viabilizar o projeto em ação. 
Após a discussão e amadurecimento sobre a temática de cada grupo, pensou-se no questionário a fim de levantar posicionamentos dos estudantes da escola acerca dos diferentes temas. Nessa etapa, os estudantes da pósgraduação assumiram importante papel, visto que esse procedimento exigiu ampla discussão e aprofundado no âmbito da disciplina que cursavam no PPGE/FE/UFG.

A adequação da linguagem para exposição dos conteúdos era essencial naquele momento. Nesse sentido, foi trabalhado com os grupos o que vinha a ser um questionário, a composição de suas partes, bem como os tipos de questôes e a importância da distribuição destas. Trabalhou-se a questão da abordagem e os cuidados necessários para condução do inquérito. Em termos estratégicos, para a proposição do instrumento, os estudantes da pósgraduação tiveram de se responsabilizar por todo o processo de acompanhamento.

Para além do instrumento e as estratégias de campo, era, pois, necessário fazer uma formação específica para uso de ferramentas tecnológicas: construção do questionário online, aplicação por meio de um dispositivo móvel (celular ou tablet). Para a fase do tratamento dos dados, utilizou-se a planilha eletrônica Excel, disponível nos computadores/notebooks em um laboratório de informática da escola. A formação para essa etapa foi desenvolvida pela professora de matemática da escola.

Cada grupo organizado, além de escolher a temática abordada, aprofundar sobre ela, elaborar o instrumento, promover a sua aplicação, fazer o tratamento dos dados, se reuniram para compor a etapa de análise e produção do relatório do estudo.

Concluir que a proposta inicial - ensino de estatística - foi contemplada com êxito é uma avaliação tímida do projeto em questão. Tão importante (para não se incorrer no julgamento de "mais importante") quanto o resultado do projeto (aprendizagem e apropriação ampliada do significado do estudo sobre as diferentes temáticas e a relação com a estatística), foi a mudança provocada por ele.

O projeto proporcionou aos estudantes da pós-graduação, aos professores e alunos da escola, bem como a equipe gestora momentos de formação, com envolvimento e engajamento. $\mathrm{Na}$ avaliação de um grupo dos estudantes da pós-graduação, em depoimento, a proposta construída a várias mãos, de característica transdisciplinar, "possibilitou compreender que a formação é um processo permanente, o qual necessita acontecer entre as instituiçóes educacionais de ensino regular e superior, integrado no cotidiano dos professores e das escolas, mantendo uma estreita relação entre os projetos 
educacionais e organizacionais" e reflete sobre a "emergência de práticas democráticas de participação dos diferentes sujeitos na organização das instituiçóes educacionais". Isso, de acordo com a avaliação, "implica na reorganização das práticas de formação acadêmica, visto que ao estabelecer um elo entre a gestão, as práticas curriculares e as necessidades de acadêmicos", fatores que constroem espaços coletivos de trabalho e se constitui em "instrumento de formação e desenvolvimento profissional".

$\mathrm{Na}$ perspectiva de outro grupo de estudantes, e experiência se constituiu em uma ação enriquecedora sob diversos aspectos. Destaca, "o preparo, interesse e disposição dos alunos, bem como o engajamento dos professores que fazem parte do projeto. Isso reflete a seriedade da escola ao promover açóes que extrapolam os limites da sala de aula". Apresenta a importância da organização da escola para o projeto, no sentido de que "a rotina ocorreu normalmente, sem transtorno, apesar de toda a movimentação. Outro ponto de destaque foi o entendimento dos alunos sobre a necessidade de vincular atividades 'próprias' da Universidade (pesquisa e extensão) ao cotidiano escolar (tradicionalmente restrito ao ensino)".

Enquanto feedback da escola, em reunião com os professores, além da avaliação positiva da experiência apontada pelos professores e alunos participantes, sentiram-se felizes pelo trabalho desenvolvido ao longo da pesquisa. Expuseram a importância da parceria entre a educação básica e o ensino superior. Alguns professores expuseram a vontade de retomarem os estudos em nível de pós-graduação, com indicação de organização de grupos de estudos na própria escola para participação dos processos seletivos na UFG. A equipe gestora expôs que os temas eleitos pelos estudantes serão retomados no ano seguinte e contemplados no Projeto Político Pedagógico da Escola.

Para finalização deste texto, uma síntese de um trabalho desenvolvido, enquanto pesquisadores é fundamental enfatizar o envolvimento, participação e coragem de todas e todos pelo empenho em transformar a escola em um ambiente vivo, dinâmico e possível de se produzir ciência, estabelecer relaçóes e fazer amizades; em um espaço de construção de conhecimentos e fazeres essenciais para a vida para além dos muros da escola. Exaltamos, também, a postura dos discentes do PPGE/FE/UFG que, para além da dedicação em uma disciplina de pós-graduação e de desafios teórico-metodológicos, se envolveram plenamente na proposta.

Por essência, concordamos com D’Ambrósio (2011, p. 11), ao expor que uma proposta transdisciplinar, "reside numa postura de reconhecimento que não há espaço e tempo culturais privilegiados que permitam julgar e hierarquizar, como mais correto ou mais certo ou mais verdadeiro, complexos 
de explicação e convivência com a realidade que nos cerca”. Não se trata de transmissão de um saber prático que explica, por definitivo, os fenômenos naturais e sociais, mas um saber inacabado, em construção, aberto à novas propostas e intervençóes coletivas guiadas pela autonomia. É, pois, neste contexto, necessário pensar, conforme Freire (1989; 2001), em uma educação emancipadora, como fonte de transformação, como um ato político. Ademais, ainda como Freire (1985, p. 34) reafirmar a possibilidade de criar "métodos de pesquisa alternativa: aprendendo a fazê-la melhor através da ação".

\section{Referências}

BARBIER, R. A pesquisa-ação. Tradução Lucie Didio. Brasília: Plano, 2002. BESSA, D. O uso das estatísticas em economia. In: SILVA, A. S.; PINTO, J. M. (Orgs.). Metodologia das ciências sociais. Porto: Ediçóes Afrontamento, 2014, p. 79-99.

D’AMBRÓSIO, Ubiratan. Transdisciplinaridade. 2. ed. São Paulo: Palas Athena, 2001.

D’AMBRÓSIO, U. Sociedade, cultura, matemática e seu ensino. Educação e Pesquisa, São Paulo, v. 31, n. 1, jan./abr. 2005, p. 99-120.

D’AMBRÓSIO, U. A transdisciplinaridade como uma resposta à sustentabilidade. NUPEAT-IESA-UFG, v.1, n.1, jan./jun, 2011, p.1-13.

FREIRE, P. A importância do ato de ler: em três artigos que se completam. São Paulo: Autores Associados/ Cortez, 1989.

FREIRE, P. Ação cultural para a liberdade. 5a ed., Rio de Janeiro: Paz e Terra. 1981.

FREIRE, P. Conscientização: teoria e prática da libertação: uma introdução ao pensamento de Paulo Freire. Trad. Kátia de Mello e Silva. São Paulo: Cortez \& Moraes, 1979b.

FREIRE, P. Criando métodos de pesquisa alternativa: aprendendo a fazê-la melhor através da ação. In.: BRANDÃO, C. R. (Org.) Pesquisa participante. 5a ed. São Paulo: Brasiliense, 1985, p. 34-41.

FREIRE, P. Educação e Mudança. 12a Edição. Rio de Janeiro: Paz e Terra, 1979a. 
FREIRE, P. Extensão ou comunicação? $7^{\mathrm{a}}$ ed. Rio de Janeiro: Paz e Terra, 1983. FREIRE, P. Pedagogia do oprimido. 17ª ed. Rio de Janeiro: Paz e Terra, 1987. FREIRE, P. Pedagogia da autonomia: saberes necessários à prática educativa. São Paulo: Paz e Terra, 1996.

FREIRE, P. Política e educação: ensaios. 5. Ed. São Paulo, Cortez, 2001.

LIMA, R. A. S. V; GONÇALVES, P. G. F. O ensino de estatística por meio da pesquisa: uma experiência a luz da modelagem matemática. Ano 33, Vol. 02, Rio Grande do Norte: HOLOS, 2017. p. 190-198.

MORIN, A. Pesquisa-Ação integral e sistêmica: uma antropopedagogia renovada. Tradução Michel Thiollent. Rio de janeiro DP\&A, 2004

SOBREVILA, M. Didactica de la educacion técnica. Editorial Kapelusz, Buenos Aires. 1986.

THIOLLENT, M. Metodologia da pesquisa-ação. 15a Ed. São Paulo: Cortez, 2007.

Recebido em: 11 set. 2020

Aceito em: 01 dez. 2020 